\title{
Resiliência individual, prazer e sofrimento no trabalho e vínculos organizacionais: reflexões e perspectivas de pesquisas para o setor público
}

\author{
FABIO FAIAD BOTTINI ${ }^{1}$ \\ Kely César Martins de Paiva ${ }^{1}$ \\ RICARDO C. GOMES ${ }^{2}$
}

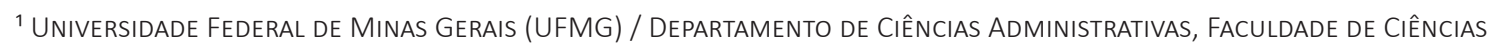 \\ ECONÔMICAS, BELO HORIZONTE - MG, BRASIL
}

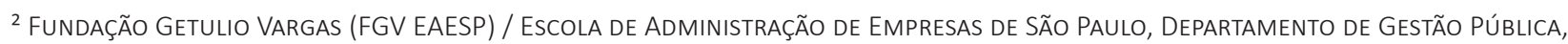

SÃO PAULO - SP, BRASIL

\begin{abstract}
Resumo
O setor público brasileiro se apresenta como um caso peculiar, dados os seus problemas e as suas idiossincrasias. Tal ambiente de trabalho afeta diretamente as pessoas, podendo ser vivenciado como fonte de prazer e/ou sofrimento, a depender de como o sujeito-trabalhador o percebe e a ele se adapta, o que tem sido analisado à luz do conceito de resiliência individual. De igual modo, o nível de resiliência pode influenciar as maneiras e os motivos pelos quais os indivíduos se vinculam às organizações em que trabalham. Essas questões têm sido alvo de atenção por parte de pesquisadores-acadêmicos e de profissionais do mercado, já que têm impacto na saúde do trabalhador e no desempenho organizacional. Neste ensaio teórico são apresentados os três temas (Resiliência individual; Prazer e sofrimento no trabalho; Vínculos organizacionais), finalizando-se com um modelo integrativo que permite uma visão mais ampla e profunda dos fenômenos e de suas possíveis inter-relações, tendo sido levantadas hipóteses que podem nortear estudos futuros. Com base nisso, propõe-se uma agenda de investigações futuras, incluindo aspectos metodológicos, a fim de estimular possibilidades epistemológicas e perspectivas de pesquisas variadas.
\end{abstract}

Palavras-chave: Resiliência individual. Prazer e sofrimento no trabalho. Vínculos organizacionais. Setor público.

Individual resilience, pleasure, and suffering at work and organizational links: reflections and perspectives of research for the public sector

\begin{abstract}
The Brazilian public sector is peculiar, given its idiosyncrasies and problems. This work environment directly affects people and can be experienced as a source of pleasure or suffering, depending on how the subject-worker perceives and adapts, which has been analyzed based on the concept of individual resilience. The level of resilience can influence how and why individuals are connected to the organizations where they work. Academic researchers and market professionals have examined these issues since they impact workers' health and organizational performance. In this theoretical essay, the three themes (Individual resilience; Pleasure and suffering at work; Organizational links) are presented. Also, the study offers an integrative model that allows a broader and deeper view of the phenomena and their possible interrelations, raising hypotheses that can guide future studies. A future research agenda, including methodological aspects, is proposed to stimulate epistemological possibilities and varied research perspectives.
\end{abstract}

Keywords: Individual resilience. Pleasure and suffering at work. Organizational links. Public sector.

\section{Resiliencia individual, placer y sufrimiento en el trabajo y lazos organizacionales: reflexiones y perspectivas de investigación para el sector público}

\section{Resumen}

El sector público brasileño presenta un caso peculiar, dados su idiosincrasia y sus problemas. Este ambiente de trabajo afecta directamente a las personas y puede ser experimentado como una fuente de placer y/o sufrimiento, dependiendo de cómo el sujeto trabajador lo perciba y se adapte a él, lo cual ha sido analizado a la luz del concepto de resiliencia individual. Asimismo, el nivel de resiliencia puede influir en las formas y razones por las cuales los individuos se vinculan con las organizaciones donde trabajan. Estos temas han sido objeto de atención por parte de investigadores académicos y profesionales del mercado, ya que tienen un impacto en la salud de los trabajadores, así como en el desempeño organizacional. En este ensayo teórico se presentan los tres temas (Resiliencia individual; Placer y sufrimiento en el trabajo; Lazos organizacionales), terminando con un modelo integrador que permite una visión más amplia y profunda de los fenómenos y sus posibles interrelaciones. Además, se plantean hipótesis que pueden guiar futuros estudios. A partir de ello, se propone un programa de investigaciones futuras, incluidos los aspectos metodológicos, a fin de estimular las posibilidades epistemológicas y las variadas perspectivas de investigación.

Palabras clave: Resistencia individual. Placer y sufrimiento en el trabajo. Lazos organizacionales. Sector público. 


\section{INTRODUÇÃO}

As mudanças causadas no ambiente empresarial e no mundo do trabalho pela globalização, pelo avanço tecnológico constante e pela competitividade crescente levam os indivíduos a planejar cada vez mais suas carreiras, estabelecendo metas profissionais e utilizando estratégias para alcançá-las (Moura, Silva \& Carvalho, 2019). Isso também ocorre na administração pública brasileira, cujas demandas variadas e crescentes ensejaram discussões sobre tamanho, legitimidade, eficiência e desempenho do Estado (Filardi, Castro \& Zanini, 2020).

Mais pressões por tempo e resultados, assim como o medo e a ansiedade, trouxeram impactos variados para os trabalhadores, como síndrome de burnout (Pfeffer, 2018), estresse ocupacional, mal-estar no trabalho (Gaulejac, 2007) e outras situações envolvendo violências psíquicas e físicas (Hirigoyen, 2011). Com tudo isso, a questão do prazer e do sofrimento passou a desempenhar um papel importante nos debates sobre o mundo laboral. $\mathrm{O}$ ambiente de trabalho afeta diretamente os indivíduos, que podem percebê-lo e vivenciá-lo como nocivo ou saudável, em termos mentais e físicos, independentemente de seus níveis de escolaridade, ocupação, segmentos de negócios, localidades, faixas etárias, entre outros elementos (Pfeffer, 2018).

A reação dos indivíduos a tais demandas parece depender da forma como ele se adapta ou não a tais transformações, típicas do mundo contemporâneo (Benedicto, Brito \& Lima, 2005), em especial no âmbito do trabalho. Nesse contexto, indivíduos mais resilientes tendem a conseguir realizar suas funções e manter condições de trabalho saudáveis. Em tempos de incertezas econômicas e competitividade intensa, as organizações que promovem a resiliência em seus trabalhadores têm uma clara vantagem em relação às outras (Malik \& Garg, 2018). A resiliência, ou seja, a capacidade de absorver e reagir a situações desconfortáveis e desafiadoras, portanto, é imperativa nesse ambiente (Irigaray, Paiva \& Goldschmidt, 2017).

Estudar resiliência nas organizações ajuda a entender as novas convenções no labutar humano e a identificar o novo profissional, a importância dele nessa organização (Teixeira \& Queiroz, 2013) e os impactos diretos na forma como (e nos motivos pelos quais) os trabalhadores criam seus vínculos com suas organizações.

Sobre os vínculos organizacionais, primeiramente se destaca o comprometimento, o qual adquiriu uma grande importância, entre estudiosos e profissionais, em razão de ser operacionalizável em termos empíricos e de se apresentar como possível preditor de performances individuais favoráveis aos atores sociais no trabalho. Por isso, o referido conceito tem sido intensamente analisado e debatido nas últimas décadas (Mariano \& Moscon, 2018). Além do comprometimento, apresentam-se também o entrincheiramento e o consentimento.

Por um lado, muitos trabalhadores pensam em largar seus empregos, mas mudam de ideia por causa da segurança no longo prazo, haja vista demissões generalizadas e crescentes, além da falta de oportunidades no mercado de trabalho. Tal postura remete ao entrincheiramento, uma metáfora que se relaciona à continuidade de profissionais num trabalho ou numa carreira em razão de a mudança Ihes ser impossível ou desvantajosa (Silva, Lima \& Leone, 2015). Por outro, a restrição velada à liberdade pode fazer com que o trabalhador apresente um comportamento concordante com as políticas da empresa, num embate travado entre a ambiguidade do comportamento e a sobrevivência aos acontecimentos. Dessa forma, a passagem do tempo é um importante fator que traz o consentimento do sujeito aos modos de gestão, tornando-o mais disponível e submisso à sua chefia e à organização (Grisci, Cigerza \& Hofmeister, 2006).

Em relação a resiliência, vínculos organizacionais, prazer e sofrimento, o setor público apresenta contornos diferenciados, em especial no Brasil, onde certas proteções legais se mantêm, bem como comportamentos contraproducentes que carecem de gestão e liderança (Bergue, 2019). A gestão pública vive uma realidade difícil graças às crises política e econômica atuais, mas tem longa história como área de pesquisa e de prática de grande interesse por parte de pesquisadores brasileiros (Aguiar \& Santos, 2017). Esse setor tem sido amplamente questionado diante de ineficiências decorrentes de um excessivo aparato burocrático e do baixo engajamento de dirigentes e servidores (Vidal \& Rodrigues, 2016), apesar de esforços em torno do desenvolvimento de líderes e competências específicas para tal setor (Bergue, 2019). Os servidores, exercendo função gerencial ou não, podem ser afetados, como mencionado antes, pelas experiências cotidianas em que o sofrimento se sobrepõe ao prazer e a resiliência não se mostra suficiente para manter os níveis de produtividade e qualidade almejados, tendo em mente as estruturas hierárquicas e os processos burocratizados típicos do setor (Bergue, 2019). 
Como os estudos sobre os vínculos organizacionais ainda necessitam de maior exploração - uma vez que as pesquisas sobre comprometimento, que já tinham um histórico no país, abriram espaço para discussão do entrincheiramento e do consentimento (Balsan, Kneipp, Tonin \& Costa, 2016) -, esta reflexão vai ao encontro de uma agenda de pesquisa em aberto, a qual versa sobre comprometimento, entrincheiramento (Santos, 2017) e consentimento (Tomazzoni, Costa, Antonello \& Rodrigues, 2020). O mesmo ocorre com as investigações sobre resiliência (Irigaray et al., 2017), sobretudo no setor em foco (Carvalho, Teodoro \& Borges, 2015). Já as pesquisas sobre prazer e sofrimento no trabalho têm uma trajetória um pouco mais consolidada no país, inclusive no escopo do setor focalizado (Aguiar \& Santos, 2017). No entanto, as demandas atuais do setor público, que incluem ameaças a direitos e sobrecarga de trabalho decorrentes de aposentadorias e dificuldades de contratações, incitam reflexões em torno de possíveis conexões com outras temáticas tratadas no campo do comportamento organizacional.

Diante desse contexto e das temáticas envolvidas, emerge a discussão em torno de relações de causalidade entre resiliência individual, prazer e sofrimento no trabalho, além de vínculos organizacionais. Para sustentá-la, este ensaio se divide nas seguintes partes: esta introdução, as referências conceituais dos construtos centrais - resiliência individual, prazer e sofrimento no trabalho, assim como vínculos organizacionais -, argumentações em torno das possíveis relações entre construtos e proposição do modelo integrativo, bem como perspectivas de pesquisa e reflexões finais do ensaio.

\section{SOBRE RESILIÊNCIA INDIVIDUAL}

À luz dos desafios impostos pelo mercado e pela sociedade, o interesse tanto de pesquisadores quanto de profissionais na resiliência no ambiente de trabalho vem crescendo na última década (Hartmann, 2018), na tentativa de compreender como as pessoas lidam com as adversidades (Rogge \& Lourenço, 2015) e, como resultado, podem experimentar um declínio em seu desempenho (Stoverink, Kirkman, Mistry \& Rosen, 2018) e consequências no seu bem-estar.

O conceito de resiliência é oriundo da engenharia, mais especificamente dos primeiros estudos sobre a elasticidade de materiais (Sabbag, 2017). Na psicologia, o começo da discussão sobre resiliência se deu na década de 1970 (Irigaray et al., 2017), sendo recentemente assimilado pela administração, focalizando a capacidade de se adequar a mudanças significativas nas organizações (Irigaray et al., 2017; Sabbag, 2017). Nesse campo do conhecimento, dois níveis de análise da resiliência têm sido delineados: o das pessoas no ambiente organizacional e o das organizações. Estudar a resiliência no referido campo permite a exploração de fatores que impactam diretamente a performance das empresas em seus (macro) ambientes e das pessoas em seus (micro e meso) ambientes profissionais, com influência nos resultados organizacionais de curto e longo prazos (Irigaray et al., 2017).

Focando na resiliência individual e considerando a complexidade do comportamento humano, suas reações, satisfações, insatisfações, fragilidades e medos que tensionam o aparelho psíquico, a resiliência se torna mais um mecanismo de defesa ou de enfrentamento de adversidades nos campos pessoal e profissional (Vieira \& Oliveira, 2017), afinal

a resiliência não é um processo linear, determinado de antemão a partir de certas causas que produzem sempre e necessariamente os mesmos efeitos. Depende das interações complexas e nunca previsíveis de inumeráveis variantes. Mas é favorecida por dois elementos imprescindíveis, embora nem sempre suficientes por si só: vínculo e sentido. É o próprio sujeito que promove a sua resiliência, quando encontra vínculos significativos que Ihe permitam reconstruir o sentido. Os outros, então, passam a representar o papel de tutores de resiliência (Condorelli, Guimarães \& Azevedo, 2010, p. 116).

Para fins deste ensaio, entende-se resiliência como um fenômeno caracterizado por resultados positivos de adaptação ante experiências negativas, o qual possibilita a superação de situações de estresse e adversidades (Carvalho et al., 2015). Assim, a investigação de fatores de risco e de proteção em interação é condição para analisá-la. A expressão "em interação" destaca o caráter ativo da resiliência, ao contrário de uma pressuposta passividade em apenas não ser prejudicado em meio aos desconfortos, mas se aperfeiçoando por meio deles (Taleb, 2012).

Apesar de críticas no sentido de submissão do trabalhador a condições precárias e/ou violentas no espaço laboral, o conceito de resiliência enseja desnudar as razões subjacentes dessa experiência humana face às adversidades, o que instiga pesquisadores críticos a reexaminar as próprias assunções acerca do tema (Van Breda, 2018). 
Considerando, sob esta ótica, a resiliência no contexto de trabalho, pode-se dizer que os riscos são representados pelas situações de tensão, pressão e mudança presentes no meio organizacional e que os mecanismos de proteção ocorreriam, não somente em virtude das características pessoais dos trabalhadores, mas também das condições do meio, em termos de suporte social dos colegas de trabalho, do suporte organizacional (provido pela estrutura de poder da organização, divisão das atribuições, seu dinamismo funcional, infraestrutura material etc.) e apoio dos familiares (recursos intra e extraorganizacionais) (Carvalho et al., 2015, p. 208).

Desse modo, a forma como o indivíduo reage a situações e tensionamentos cotidianos podem levá-lo a vivências de prazer e/ou de sofrimento no trabalho, bem como afetar seus vínculos com a própria organização.

\section{SOBRE PRAZER E SOFRIMENTO NO TRABALHO}

O trabalho dentro da sociedade é fundamental não só para o homem produzir e sobreviver, mas também para se realizar e estruturar psiquicamente. A forma como o sujeito relaciona esses aspectos subjetivos e objetivos pode resultar em vivências de prazer e/ou de sofrimento no espaço laboral (Salgado, Aires \& Santos, 2018), os quais são objetos da psicodinâmica do trabalho, que focaliza o relacionamento entre a organização do trabalho e o trabalhador, considerando dimensões de contexto e de conteúdo na referida organização (Aguiar \& Santos, 2017).

A trajetória da psicodinâmica do trabalho é marcada por três fases articuladas, consideradas complementares (Dejours, 2007). A primeira, da década de 1980, pautada no trabalho precursor de Dejours (1987), que versava sobre psicopatologia do trabalho, se concentrou na origem do sofrimento no confronto do sujeito-trabalhador com a organização do trabalho. A segunda, de meados da década de 1990, foi o momento de criação/construção de uma abordagem particular e pioneira para estudar o trabalho, nomeada psicodinâmica do trabalho, focalizando as vivências de prazer-sofrimento como dialéticas e inerentes a todo contexto de trabalho, bem como as estratégias usadas pelos trabalhadores para confrontar a organização do trabalho, manter a saúde, evitar o adoecimento e assegurar a produtividade. Por fim, a terceira, do final da década de 1990 até os dias atuais, caracterizou a consolidação e a propagação da psicodinâmica como abordagem científica capaz de explicar os efeitos do trabalho sobre os processos de subjetivação, as patologias sociopsíquicas e a saúde dos trabalhadores.

Segundo Dejours (2007), a normalidade - mesmo que apenas aparente - é uma conquista que advém da criação de estratégias individuais e coletivas de defesa dos trabalhadores no que diz respeito ao sofrimento no trabalho e sua possível ressignificação a partir de motores psíquicos e sociais do prazer. Esses "motores" estão diretamente relacionados à resiliência individual, conforme tratada antes.

No Brasil, as pesquisas sobre psicodinâmica do trabalho ganharam vulto com os estudos seminais de Mendes (2007). Para a autora, os marcos e as inquietudes do mundo do trabalho e seu papel nas condições de saúde e no processo de adoecimento dos trabalhadores estimulam os pesquisadores a realizar, sob tal perspectiva, numerosas pesquisas, de diversas naturezas, sobre modus operandi do trabalho e de sua relação com as pessoas (Mendes \& Morrone, 2010).

Diante do exposto, e para fins deste ensaio, entende-se prazer no trabalho como as vivências do trabalhador caracterizadas pela presença de pelo menos um dos seguintes sentimentos: reconhecimento, identificação, orgulho pela atividade em si, realização e liberdade (Mendes \& Morrone, 2010). Já o sofrimento no trabalho é concebido como as vivências do trabalhador caracterizadas pela presença de pelo menos um dos seguintes sentimentos: medo, insatisfação, insegurança, estranhamento, desorientação, impotência diante das incertezas, alienação, vulnerabilidade, frustração, inquietação, angústia, depressão, tristeza, agressividade, impotência para promover mudança, desgaste, desestímulo, desânimo, sentimento de impotência, desgaste físico ou emocional, desvalorização, culpa, tensão e raiva (Mendes \& Morrone, 2010).

Como este ensaio focaliza o setor público e, portanto, os servidores públicos, parte-se do pressuposto de que as mudanças ocorridas nos últimos anos no modelo de gestão e na concepção de Estado e de governo implicaram transformações nas relações cotidianas de trabalho dentro dos órgãos públicos, favorecendo o surgimento de conflitos em face do "novo". Assim, abre-se espaço para problematização do objeto, já que é necessário lançar luzes para o que acontece nas relações de trabalho nessas mudanças de modelos gerenciais, considerando as lentes da psicodinâmica do trabalho 
profícuas em termos de promoverem outras compreensões da dinâmica intersubjetiva diante dos conflitos gerados pelo confronto entre o desejo do sujeito-trabalhador e os modelos de organização e gestão do trabalho implantados (Aguiar \& Santos, 2017).

Tais modelos podem ou não contribuir para o fortalecimento dos laços entre trabalhador e organização, de modo que o primeiro intencione nela permanecer ou considere outras oportunidades de trabalho ou sustento.

\section{SOBRE VÍNCULOS ORGANIZACIONAIS}

Compreender a forma com que os vínculos organizacionais se articulam formando diversos padrões que impactam a performance dos trabalhadores é fundamental para a elaboração de estratégias de criação, desenvolvimento e fortalecimento de vínculos, de modo a incentivar o desenvolvimento de padrões de vínculos benéficos em relação a esse aspecto, tanto para os indivíduos quanto para as empresas (Rodrigues \& Álvares, 2020).

O conceito de comprometimento dá início à evolução do tema "vínculos organizacionais". O impulso inicial para pesquisas aconteceu nos anos 1970 e, no Brasil, em meados da década de 1980. O fato de não haver uma única definição para comprometimento organizacional fez com que os diversos conceitos adotados tivessem em comum um elemento: um estado psicológico positivo que caracteriza a relação do trabalhador com a empresa e gera impacto no seu desempenho (Bastos \& Aguiar, 2015). Considerando três bases do comprometimento - afetiva, de continuação e normativa -, o modelo tridimensional de Meyer e Allen (1987) foi pioneiro no assunto, sendo bastante adotado em pesquisas no Brasil (Bastos \& Aguiar, 2015) e no exterior (Simosi, 2013).

Com a evolução das pesquisas sobre o assunto no Brasil, percebeu-se a incoerência em considerar comprometidos indivíduos com diferentes condições de permanência e outros problemas de ordens teórica e prática, favorecendo que alguns pesquisadores revisassem a delimitação dos vínculos com a organização (Rodrigues \& Bastos, 2009). Assim, as bases de continuação e normativa foram colocadas à parte, partindo-se para a retomada de uma definição mais restrita do construto comprometimento organizacional, focado na base afetiva (Bastos \& Aguiar, 2015). Neste ensaio, o conceito de comprometimento reflete o vínculo pautado na crença e na aceitação de valores e objetivos da organização, assim como na intenção de se esforçar em prol dela e no desejo de manter o vínculo com a organização (Bastos \& Aguiar, 2015).

O vínculo instrumental, por sua vez, foi questionado como real comprometimento, por isso passou a ser articulado por outro conceito, o de entrincheiramento, que se relaciona à tendência do trabalhador a permanecer na empresa por causa das possíveis perdas associadas à sua saída, como benefícios, vantagens pecuniárias, investimentos no ajustamento do cargo, networks e outras vantagens que restrinjam a percepção de alternativas de trabalhos que as possam suprir (Rodrigues \& Bastos, 2015). Infelizmente, muitas empresas, ao adotar políticas e práticas de gestão de pessoas inadequadas, intensificam as ocorrências de entrincheiramento em seus quadros por diversos modos, inclusive por meio de pagamento de altos salários e benefícios. Nessa mesma linha, Taleb (2018) sustenta, de forma crítica, que tais vínculos se traduzem em status diferenciado e acabam se consolidando como um tipo alternativo e curioso de "escravidão". Para Rodrigues e Bastos (2015), quanto maior for a percepção do trabalhador de que está adaptado à posição social e aos arranjos burocráticos, em conjunto com a avaliação de alternativas limitadas, maior sua possibilidade de se sentir ou estar entrincheirado. Dessa forma, para este ensaio, o entrincheiramento do indivíduo é um vínculo que envolve a avaliação cognitiva sobre a possível perda de investimentos feitos pelo trabalhador na empresa e sobre a escassez de alternativas no mercado de trabalho (Rodrigues \& Bastos, 2015).

Por último, proveniente da base normativa, nasceu o conceito de "consentimento". Num contexto no qual o tempo é rentabilizado e perpassado pela perspectiva do imediatismo, do curto prazo, as diversas influências da percepção individual sobre a memória humana - como distorção, minimização, naturalização, generalização e despersonalização dos acontecimentos - podem ajudar a suavizar os atos da gestão de mais difícil aceitação que poderiam estimular a resistência dos trabalhadores pela comparação com os modos de trabalhar anteriores (Grisci et al., 2006). Logo, entendemos consentimento organizacional como a tendência do indivíduo de obedecer às demandas da organização, personificadas por seus chefes. Pressupõe-se que o cumprimento de ordens e normas acontece graças às relações de poder e autoridade que se estabelecem entre superior e subordinado, bem como por acreditar que os superiores sabem melhor o que deve ser feito (Silva \& Bastos, 2015). 
Investigar a qualidade dos vínculos entre indivíduo e organização é imprescindível para o entendimento das relações estabelecidas no ambiente laboral, sendo que tais relações podem interferir em várias dimensões da dinâmica organizacional, tanto na qualidade de vida do indivíduo quanto na efetividade, na produtividade e na competitividade da empresa. Na qualidade dos vínculos, podem-se verificar envolvimento, identificação, apego, satisfação, motivação, centralidade, entre outros elementos, os quais, diante de muitas combinações entre si, auxiliam na definição de alguns comportamentos do indivíduo. Pode-se considerar a qualidade do vínculo como um reflexo não apenas de valores intrínsecos e atitudinais, mas também de uma resposta à cultura da organização, podendo resultar no valor que o trabalhador atribui à empresa e às consequentes relações de trabalho (Vidal \& Rodrigues, 2016).

Considerando-se o setor público brasileiro, com centenas de cargos e de carreiras, desigualdades de distribuição salarial, distorções orçamentárias, baixa autonomia gerencial, entre outras características (Peci, 2020), os vínculos tendem a guardar particularidades, daí o modelo proposto focalizar tal setor. As relações entre os construtos no referido lócus são aprofundadas a seguir.

\section{POSSÍVEIS RELAÇÕES ENTRE OS CONSTRUTOS E PROPOSIÇÃO DO MODELO INTEGRADO}

A subjetividade abrange não só a mente e o corpo do trabalhador, mas um conjunto de sentimentos, sofrimentos, ambições, fragilidades e conflitos que o acompanharão onde estiver (Vieira \& Oliveira, 2017), dentro e fora do ambiente de trabalho. De igual maneira, o grau de resiliência desse trabalhador está ligado à sua história de vida; a seus projetos, sonhos e anseios; às suas esperanças e realizações - aspectos em grande parte ignorados pelas organizações, porém fortemente conectados com o prazer e, por conseguinte, com o sofrimento no cotidiano laboral.

O sofrimento é visto como uma espécie de drama, que mobiliza o sujeito no mundo e no trabalho, em busca das condições de saúde. Nem o sofrimento nem as estratégias de defesas individuais e coletivas são patológicos, mas uma saída para o alcance da saúde. Nessa perspectiva, intervir na organização do trabalho significa contribuir para o processo da saúde, que permite aos sujeitos subverter o sofrimento, transformando-o em algo com sentido, inteligibilidade e ação. Isso não significa anular o sentimento, mas transformá-lo no prazer da reapropriação do vivido pela ação (Martins \& Honório, 2014, p. 848).

Assim, prazer e sofrimento no trabalho contêm elementos tanto objetivos quanto subjetivos que carecem de compreensão e gestão, dadas as contradições que lhes são inerentes, aqui observadas em suas contradições e complementaridades. Diante disso, entende-se haver uma relação direta e positiva entre a resiliência individual do trabalhador e o prazer no trabalho, graças à importância deste último na vida, de modo mais amplo, no que tange à realização pessoal e profissional e no que diz respeito à identidade como sujeito psicológico e social, que produz e se reconhece em relação aos outros (Mendes \& Morrone, 2002). Um exemplo disso foi apresentado num estudo no setor público, com policiais militares do sexo feminino, no estado de Minas Gerais, cujos resultados relativos ao prazer foram mais expressivos do que os ligados ao sofrimento. Contudo, elas indicaram a necessidade de resiliência contínua para isso, inclusive no que tange à superação de resultados frente a colegas do sexo masculino e à inviabilização dos próprios traços de feminilidade (Carmo, Guimarães \& Caeiro, 2016).

Outro fator relevante trata das condições nas quais o trabalho é realizado, de transformá-lo em algo penoso e doloroso, levando o sujeito ao sofrimento advindo do confronto entre sua subjetividade e as restrições de contextos socioculturais e ambientais, de relações sociais e da própria organização do trabalho. Exemplo disso é o assédio moral e outras formas de violência nos espaços laborais - estudos explicitam que a resiliência pode atenuar dores de humilhações e desventuras impostas aos trabalhadores (Bacchi, Carvalho \& Pinto, 2012).

Há uma relação direta e negativa entre a resiliência individual do trabalhador e o sofrimento no trabalho. Os trabalhadores mais resilientes ressignificam o sofrimento e o tomam como um estímulo para a mudança, para a construção de estratégias de defesa, já que, em si, ele não é patológico, mas pode alertar o sujeito para o desenvolvimento de atitudes que visem evitar o adoecimento (Mendes \& Morrone, 2002). Nesse caso, aponta-se o exemplo de um estudo com juízes e servidores do Poder Judiciário sobre resiliência e controle do estresse no trabalho, no qual se constatou que, quanto maior as habilidades em analisar as causas das adversidades, controlar suas emoções, assumir uma postura otimista diante da vida, entender as 
razões que fazem as outras pessoas agirem de determinada forma e acreditar que têm capacidade para honrarem as tarefas a eles destinadas, menores os riscos de desenvolver estresse crônico e patologias correlatas (Oliveira, 2007). Ou seja,

frente a estressores, os indivíduos adotam estratégias de enfrentamento (coping), que igualmente apresentam componentes cognitivos, comportamentais e emocionais. Essas estratégias decerto sofrem influência da personalidade. Mas é o conjunto dos traços de personalidade e das estratégias de enfrentamento que formam a resiliência do indivíduo, enquanto modo de encarar a vida e aptidão para enfrentar situações de estresse (Sabbag, 2017, pp. 13-14).

De igual modo, recomendações crescentes e gerais à área de gestão de pessoas de organizações incitam a busca pela interatividade e pela comunicação com o objetivo de reter talentos, compartilhar experiências e buscar motivação contínua (Costa \& Moura, 2018). Tais sugestões implicam diretamente os vínculos organizacionais dos trabalhadores, em especial no comprometimento afetivo deles, afinal a autogestão das carreiras pode ter efeitos ambíguos nesse sentido, bem como a terceirização e os processos de redução de pessoal, que costumam fragilizar os contratos psicológicos estabelecidos entre organizações e empregados. De modo semelhante, a diminuição do comprometimento organizacional pode advir da organização do trabalho em torno de equipes autônomas, com profissionais comprometidos entre si. Há ainda que refletir sobre o enfraquecimento crescente da maior parte dos sindicatos, que conduzem a um afrouxamento das relações coletivas e potencializam o individualismo, podendo ter efeitos positivos em termos de comprometimento organizacional e de carreira pessoal (Borges-Andrade \& Pilati, 2001). Assim, percebe-se um movimento arriscado, do ponto de vista da organização, em fomentar um envolvimento afetivo e, ao mesmo tempo, estabelecer políticas de pessoal que se sustentam na volatilidade do trabalho (Borges, Lima, Vilela \& Morais, 2004).

Diante do exposto, depreende-se uma relação direta e positiva entre a resiliência individual do trabalhador e seus vínculos organizacionais. Ou seja, quanto mais resilientes forem os indivíduos, mais se ligam afetivamente à organização e desconsideram deixá-la. Assim, trocas materiais e simbólicas satisfatórias entre organização e trabalhador são necessárias para gerar maior qualidade de vida no trabalho, bem como maior produtividade (Vidal \& Rodrigues, 2016).

No caso de servidores públicos brasileiros, existe uma diversidade de carreiras com remunerações, áreas de atuação, incentivos e trajetórias de desenvolvimento distintos. Isso torna essas carreiras atrativas e disputadas inclusive quando têm mesmo patamar remuneratório (Santos, 2017). Além disso, o servidor público brasileiro conta com proteções institucionais que podem contribuir para o desenvolvimento de sua resiliência, na medida em que qualquer um pode recorrer a certos expedientes (processos administrativos, licenças etc.) para fazer face a possíveis ameaças, bem como diminuir seu sofrimento e favorecer sua adaptação, ou ainda a presença de que certos tipos de reconhecimentos profissionais e liberdades de expressão que promovem seu prazer no trabalho. Além disso, os vínculos organizacionais podem ser fortalecidos - ou enfraquecidos - mediante usos utilitaristas de tais expedientes, favorecendo-se pelas relações sociais que se travam dentro de certos espaços laborais. Por exemplo: um estudo comparativo entre servidores brasileiros e noruegueses apontou que, não obstante as diferenças de cultura organizacional e nacional, a resiliência exerce um papel relevante nos resultados de socialização (Carvalho et al., 2015), o que indica possibilidades diversas em termos dos vínculos organizacionais, quer seja considerado o comprometimento, o consentimento, quer seja considerado o entrincheiramento, com diferenciados impactos em termos de desempenho (Santos, 2017).

Diante das relações observadas na literatura e em estudos brasileiros, os conceitos de resiliência individual, prazer e sofrimento no trabalho, bem como vínculos organizacionais, costumam ser tratados separadamente, apesar de as recomendações de pesquisas serem profícuas em torno do desenvolvimento de abordagens integrativas, que os estudem em conjunto, visando, inclusive, contribuir para a gestão de pessoas e para o serviço público em especial, no sentido de implementar políticas que propiciem uma relação mais saudável e produtiva entre as pessoas e suas atividades.

Assim, visando à proposição de um modelo integrativo, apresentam-se as seguintes hipóteses:

1. Há uma relação positiva entre a resiliência individual do trabalhador e o prazer no trabalho.

2. Há uma relação negativa entre a resiliência individual do trabalhador e o sofrimento no trabalho.

3. Há uma relação positiva entre a resiliência individual do trabalhador e seu comprometimento.

4. Há uma relação positiva entre a resiliência individual do trabalhador e seu consentimento.

5. Há uma relação positiva entre a resiliência individual do trabalhador e seu entrincheiramento. 
6. Há uma relação positiva entre o prazer do trabalhador e seu comprometimento.

7. Há uma relação positiva entre o prazer do trabalhador e seu consentimento.

8. Há uma relação positiva entre o prazer do trabalhador e seu entrincheiramento.

9. Há uma relação negativa entre o sofrimento do trabalhador e seu comprometimento.

10. Há uma relação negativa entre o sofrimento do trabalhador e seu consentimento.

11. Há uma relação negativa entre o sofrimento do trabalhador e seu entrincheiramento.

Tais hipóteses podem ser visualizadas no modelo proposto para estudo integrado dos construtos analisados na Figura 1:

Figura 1

Modelo integrativo entre resiliência individual, prazer e sofrimento no trabalho e vínculos organizacionais

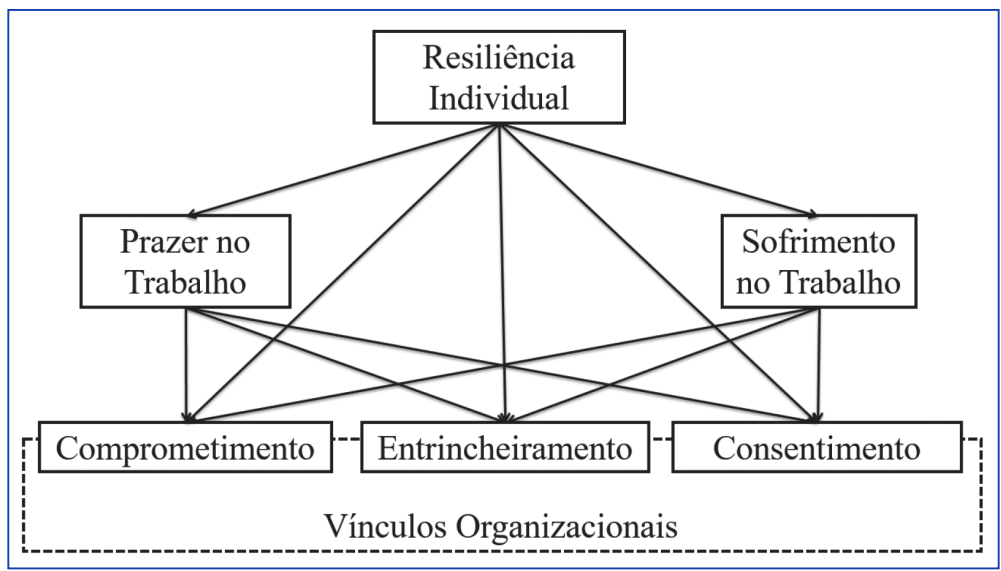

Fonte: Elaborada pelos autores.

Tais hipóteses também podem ser repensadas em termos de perguntas norteadoras em estudos de caráter analítico, interpretativista. Tal movimento abre espaço para uma agenda de investigações futuras que inclui concepções e abordagens metodológicas diversas, bem como métodos e possibilidades de triangulações teóricas e metodológicas, nos moldes indicados por Collis e Hussey (2005). Partes dessas possibilidades estão dispostas a seguir.

\section{PERSPECTIVAS DE PESQUISAS FUTURAS E REFLEXÕES FINAIS}

Os temas aqui discutidos são complexos e podem ser concebidos e analisados por diferentes perspectivas. No entanto, em que pese o modelo proposto, algumas possibilidades ontológicas, que privilegiem o realismo-objetivo ou o nominalismo-subjetivo, e epistemológicas - funcionalista, positivista, estruturado, causal, ou analítico, fenomenológico, relativo, relacional - parecem se impor, usualmente pela própria forma de construir o problema de pesquisa e pela condução das investigações, conceitual e pragmaticamente falando.

A abordagem qualitativa, dada sua profundidade, se aproxima da complexidade que está presente nos temas apresentados, mas pode incorrer em limitações no que diz respeito a comparações e generalizações (Silva, Medeiros \& Enders, 2011). A abordagem quantitativa está mais avançada em relação aos aspectos que a qualitativa não consegue apoiar, mas pode incorrer na superficialidade das análises, não atingindo a essência dos fenômenos (Silva et al., 2011), ainda mais quando analisados de modo integrado. Por isso, quanto a perspectivas metodológicas para futuras pesquisas, sugere-se que sejam utilizadas a abordagem quantitativa a qualitativa, bem como métodos conjugados ou triangulações (Collis \& Hussey, 2005). 
No que tange à abordagem quantitativa, aconselha-se a adoção de técnicas estatísticas uni, bi e multivariadas, incluindo-se modelagem de equações estruturais, a fim de verificar os potenciais efeitos de uma ou mais variáveis nas outras (Hair, Black, Babin \& Anderson, 2004). Esta, inclusive, seria a mais indicada para a validação quantitativa do modelo integrativo proposto neste ensaio. Ao testar a influência e a significância entre as variáveis dos construtos integrados, há possibilidade de verificar o tipo de associação (direta, mediadora ou moderadora) que melhor descreveria as inter-relações entre elas (Hair et al., 2004). De posse dos resultados de investigações com essa envergadura, seria possível desenvolver outros instrumentos de coleta de dados mais amplos (inventários, escalas, questionários), visando à construção de modelos mais robustos.

Em relação aos vínculos organizacionais, os três têm escalas validadas recentemente: Medida de Comprometimento Organizacional de Bastos e Aguiar (2015), Escala de Consentimento Organizacional de Silva e Bastos (2015) e Medida de Entrincheiramento Organizacional de Rodrigues e Bastos (2015). As duas primeiras são unidimensionais; a terceira, de entrincheiramento, é tridimensional, mensurando adaptação a posição social, arranjos burocráticos impessoais e limitações de alternativas do trabalhador-respondente.

Em relação à resiliência, o conceito teria pouca aplicabilidade se não fosse possível observá-lo, analisá-lo e mensurá-lo em indivíduos (Sabbag, 2017). Nessa direção, Carvalho et al. (2015) validaram no Brasil a Escala de Resiliência para Adultos, originalmente desenvolvida por estudiosos noruegueses. Ela é composta por seis fatores: percepção de si mesmo, futuro planejado, competência social, estilo estruturado, coesão familiar e recursos sociais. Tais escalas podem ser úteis em pesquisas quantitativas pautadas no modelo integrado proposto.

Os trabalhos de Mendes (2007) abriram outra possibilidade de compreensão do fenômeno relativo à díade prazer-sofrimento no trabalho e das estratégias de defesa dos trabalhadores, transitando da concepção analítica e interpretativista, originalmente inaugurada por Dejours, para uma perspectiva funcionalista e positivista. Assim, Mendes e Ferreira (2007) propuseram quatro categorias ou dimensões de análise para o estudo da psicodinâmica, relacionadas entre si: contexto de trabalho, referente à organização, às relações socioprofissionais e às condições do trabalho; exigências do trabalho, relativas ao custo físico, cognitivo e afetivo das atividades envolvidas; sentido do trabalho, relacionadas diretamente às vivências de prazer e de sofrimento no trabalho; e efeitos do trabalho para a saúde, em termos das consequências e dos danos físicos e psicossociais desse trabalho em relação aos trabalhadores.

Tais dimensões podem ser avaliadas de modo independente com um instrumento de pesquisa chamado Inventário sobre Trabalho e Riscos de Adoecimento (Itra), amplamente utilizado em pesquisas no país. O Itra foi criado e validado por Mendes e Ferreira (2007) em ampla pesquisa com auditores fiscais da Previdência Social e, posteriormente, revalidado pelos próprios autores em pesquisa com outros servidores públicos federais (Ferreira, Santos, Paula, Mendonça \& Carneiro, 2017), o que demonstra a adequação do instrumento para investigações no serviço público.

Por sua vez, uma abordagem qualitativa permitiria compreender em profundidade os fenômenos em foco e as relações entre si, bem como aprofundar o entendimento de dados quantitativos, no caso de triangulações. Além disso, métodos analíticos qualitativos poderiam identificar outras categorias de análise e variáveis, inclusive mais pertinentes ao setor público, possibilitando o desenvolvimento de modelos mais robustos e com maior poder compreensivo e explicativo, como atentaram Abdalla, Oliveira, Azevedo e Gonzalez (2018), o que poderia reverberar em adaptações nas escalas existentes e no desenvolvimento de outras mais específicas para o setor público.

Com relação ao setor público, particularmente, consideram-se diferenças nos níveis federal, estadual e municipal, assim como nas suas áreas de atuação. Incluem-se também a administração direta e indireta, como observado por Aguiar e Santos (2017), e instituições pertencentes aos três poderes: Executivo, Legislativo e Judiciário. Relações entre comprometimento e entrincheiramento foram discutidas em outros estudos (Milhome \& Rowe, 2018), inclusive no setor público (Santos, 2017; Silva, Tomazzoni \& Costa, 2018). A análise de Botelho e Paiva (2011), realizada em instância do Judiciário de Minas Gerais, apontou possibilidades de conexões temáticas com o construto comprometimento e a necessidade de estudos triangulados. Isso foi levado a cabo, por exemplo, na pesquisa de Costa, Oliveira e Nogueira (2017), que privilegiou a abordagem quantitativa e recomendou estudos com triangulação em outras instâncias do Judiciário brasileiro. Outro exame em instituto de pesquisa indicou níveis de comprometimento diferenciados entre servidores públicos e terceirizados (Paiva, Falce \& Muylder, 2013), no qual também foi sugerido aprofundamento, o que pode ser realizado por meio de triangulação, inclusive com base no modelo teórico proposto. Em sentido semelhante estão as recomendações de estudo presentes no ensaio de Irigaray et al. (2017), que abarcam o tema resiliência e possíveis conexões temáticas, incluindo o setor público entre os campos destacados, bem como trabalhadores com vínculos trabalhistas diferenciados, como servidores, celetistas e terceirizados. 
Outro aspecto que tem relevância no cotidiano do setor público é o exercício da função gerencial, usualmente "temporária" para cargos de confiança e repleta de dificuldades quando se considera carreira técnica, o que pode ser observado na pesquisa de Dutra, Oleto, Paiva \& Rios (2016). Do mesmo modo, o desenvolvimento e a atuação de líderes (Bergue, 2019) de servidores em cargos de chefia podem ser facilitados pelo conhecimento de características individuais e preponderantes em grupos de servidores, como aquelas que dizem respeito às suas capacidades de adaptação (resiliência), às suas formas de vivenciar positiva ou negativamente o trabalho que executam (prazer e sofrimento) e ao meio pelo qual se conectam à organização, quer afetivamente (comprometimento), quer por lealdade ao gestor (consentimento), quer por falta de opções mais vantajosas (entrincheiramento). Tal conhecimento pode promover e facilitar as relações sociais e, em especial, o exercício da função gerencial e a própria gestão no serviço público.

Por fim, esses estudos indicam diferenças que precisam ser desnudadas em termos do setor público no que tange à atuação do Estado em áreas como educação, saúde e segurança pública, entre outras. Análises relevantes têm sido conduzidas em instituições federais de ensino técnico e superior a respeito dos temas aqui tratados, como é o caso de prazer e sofrimento (Dario \& Lourenço, 2018), e também são analisadas em organizações hospitalares, como abordado por Barros e Honório (2015).

A vastidão do setor público brasileiro enseja pesquisas em variados âmbitos, graças às peculiaridades pragmáticas observadas em exames anteriores, pautados em sua abrangência e alta complexidade (Cavalcante, 2018). Tais aspectos, bem como seus desdobramentos no corpo de servidores de carreira, ficam registrados como sugestões para futuras pesquisas.

Não houve a pretensão de restringir ou exaurir a discussão em torno das temáticas aqui tratadas, mas atentar no objetivo da proposição do modelo integrado e nessa agenda de pesquisa que atende a duas instâncias: à conceitual e acadêmica, visando delinear e expandir a delimitação dos construtos envolvidos por meio do modelo integrativo, e segundo à prática $\mathrm{e}$ profissional, que vislumbra fornecer insumos e subsídios para uma gestão de pessoas mais humana e eficaz no setor público.

\section{AGRADECIMENTOS}

Agradecemos ao Conselho Nacional de Desenvolvimento Científico e Tecnológico (CNPq) pelo apoio recebido. 


\section{REFERÊNCIAS}

Abdalla, M. M., Oliveira, L. G. L., Azevedo, C. E. F., \& Gonzalez, R. K. (2018). Quality in Qualitative Organizational Research: Types of Triangulation as a Methodological Alternative. Administração: Ensino e Pesquisa, 19(1), 66-98.

Aguiar, R. G., \& Santos, A. C. B. (2017). Conflitos nas relações sociais de trabalho no contexto da nova gestão pública à luz da psicodinâmica do trabalho. Race - Revista de Administração, Contabilidade e Economia, 16(esp.) 157-184.

Angelis, C. A. (2013). Uma proposta de um modelo de inovação e inteligência governamental. Revista de Administração e Inovação, 10(3), 97-324.

Bacchi, G. A., Carvalho, D. R., \& Pinto, F. R. (2012). Assédio moral e resiliência no local de trabalho. Revista Ciências Administrativas, 18(1), 301-330.

Balsan, L. A. G., Kneipp, J. M., Tonin, S., \& Costa, V. M. F. (2016). Os vínculos que o indivíduo estabelece com a organização: uma análise da produção científica brasileira. Revista de Ciências da Administração, 8(45), 25-37.

Barros, N. M. G. C., \& Honório, L. C. (2015). Riscos de adoecimento no trabalho de médicos e enfermeiros em um hospital regional matogrossense. Revista de Gestão, 22(1), 95-113.

Bastos, A. V. B., \& Aguiar, C. V. N. (2015). Comprometimento organizacional. In K. Puente-Palacios, A. L. A. Peixoto (Eds.), Ferramentas de diagnóstico para organizações e trabalho: um olhar a partir da psicologia (pp. 78-91). Porto Alegre, RS: Artmed.

Benedicto, S. C., Brito, M. J., \& Lima, J. B. (2005). Aprendizagem transformativa no espaço organizacional: uma análise da proposta andragógica da Petrobras. Organizações Rurais e Agroindustriais, 7(1), 3-36.

Bergue, S. T. (2019). Gestão de pessoas: liderança e competências para o setor público. Brasília, DF: Enap.

Borges, L. O., Lima, A. M. S., Vilela, E. C., \& Morais, S. S. G. (2004). Comprometimento no trabalho e sua sustentação na cultura e no contexto organizacional. Revista de Administração de Empresas, $3(1), 1-24$.

Borges-Andrade, J. E., \& Pilati, R. (2001). Comprometimento atitudinal e comportamental: relações com suporte e imagem nas organizações. Revista de Administração Contemporânea, 5(3), 85-106.

Botelho, R. D., \& Paiva, K. C. M. (2011). Comprometimento organizacional: um estudo no Tribunal de Justiça do Estado de Minas Gerais. Revista de Administração Pública, 45(5), 1249-1283.

Carmo, J. G. M., Guimarães, L. V. M., \& Caeiro, M. L. (2016). Prazer e sofrimento no trabalho: vivências de mulheres soldados da polícia militar. Farol-Revista de Estudos Organizacionais e Sociedade, 3(8), 1313-1357.

Carvalho, V. D., Teodoro, M., \& Borges, L. O. (2015). Resiliência no contexto de trabalho. In K. Puente-Palacios, A. L. A. Peixoto (Eds.), Ferramentas de diagnóstico para organizações e trabalho: um olhar a partir da psicologia (pp. 206-220).
Cavalcante, P. (2018). Innovations in the Federal Government During the Post-new Public Management Era. Revista de Administração Contemporânea, 22(6), 885-902.

Collis, J., \& Hussey, R. (2005). Pesquisa em administração: um guia prático para alunos de graduação e pós-graduação. Porto Alegre, RS: Bookman.

Condorelli, A., Guimarães, C. F., \& Azevedo, C. R. S. (2010). O bater das asas de uma borboleta: o papel do educador como tutor de resiliência à luz das ideias de Boris Cyrulnik. Interface - Revista do Centro de Ciências Sociais Aplicadas, 7(2), 114-131.

Costa, E. S., \& Moura, A. C. (2018). Motivação como fator de sucesso para a gestão de carreira: o papel do administrador na melhoria das relações de trabalho. Revista de Carreiras e Pessoas, 8(2), 212-226.

Costa, P. K. C., Oliveira, L. G. L., \& Nogueira, J. M. M. (2017). Comprometimento organizacional: um estudo de caso em um Tribunal de Justiça de médio porte da Região Nordeste do Brasil. In Anais do 6o Encontro de Gestão de Pessoas e Relações de Trabalho da ANPAD, Curitiba, PR.

Dario, V. C., \& Lourenço, M. L. (2018). Cultura organizacional e vivências de prazer e sofrimento no trabalho: um estudo com professores de instituições federais de ensino superior. Revista Organizações em Contexto, 14(27), 345-395.

Dejours, C. (1987). A loucura do trabalho: estudo de psicopatologia do trabalho. São Paulo, SP: Obore.

Dejours, C. (2007). Prefácio. In A. M. Mendes (Org.), Psicodinâmica do trabalho (pp. 19-22). São Paulo, SP: Casa do psicólogo.

Dutra, M. R. S., Oleto, A. F., Paiva, K. C. M., \& Rios, J. E. (2016). Comprometimento organizacional: um estudo comparativo entre gerentes e não gerentes do setor público mineiro. In Anais do 7 o Encontro de Administração Pública da ANPAD, São Paulo, SP.

Ferreira, L. B., Santos, M. A. F., Paula, K. M., Mendonça, J. M. B., \& Carneiro, A. F. (2017). Risco de adoecimento no trabalho: estudo com policiais militares de um batalhão de polícia de Brasília. Revista Eletrônica Gestão \& Sociedade, 11(29), 1804-1829.

Filardi, F., Castro, R. M. P., \& Zanini, M. T. F. Vantagens e desvantagens do teletrabalho na administração pública: análise das experiências do Serpro e da Receita Federal. Cadernos EBAPE.BR, 18(1), 28-46, 2020.

Gaulejac, V. (2017). Gestão como doença social. Aparecida, SP: Ideias e Letras.

Grisci, C., Cigerza, G. C., \& Hofmeister, P. M. (2006). Tempo, resistência e consentimento na reestruturação produtiva do trabalho bancário. Revista Eletrônica de Administração, 12(6), 622-641.

Hair, J. F., Jr., Black, W. C., Babin, B. J., \& Anderson, R. E. (2014). Multivariate Data Analysis. Harlow, UK: Pearson.

Hartmann, S. (2018). The Power of We: The Effects of Mutuality and Team Reflexivity on Team Resilience in the Workplace. Academy of Management Proceedings, 2018(1), 1-6. Recuperado de https://doi. org/10.5465/AMBPP.2018.59

Hirigoyen, M. F. (2011). Assédio moral. Rio de Janeiro, RJ: Bertrand Brasil. 
Irigaray, H. A. R., Paiva, K. C. M., \& Goldschmidt, C. C. (2017). Resiliência organizacional: proposição de modelo integrado e agenda de pesquisa. Cadernos EBAPE.BR, 15(esp.), 390-408.

Malik, P., \& Garg, P. (2018). Psychometric Testing of the Resilience at Work Scale Using Indian Sample. Vikalpa - The Journal for Decision Makers, 43(2), 77-91.

Mariano, T. L. A. B., \& Moscon, D. C. B. (2018). As relações entre as práticas de gestão de pessoas e o desenvolvimento de vínculos com a organização: um estudo em uma empresa de contabilidade. Revista Gestão e Planejamento, 19, 227-243.

Martins, A. A. V., \& Honório, L. C. (204). Prazer e sofrimento docente em uma instituição de ensino superior privada em Minas Gerais. Revista O\&S, 21(68), 835-852.

Mendes, A. M. (2007). Da psicodinâmica à psicopatologia do trabalho. In A. M. Mendes (Org.), Psicodinâmica do trabalho (pp. 23-48). São Paulo, SP: Casa do Psicólogo.

Mendes, A. M., \& Ferreira, M. C. (2007). Inventário Sobre Trabalho e Riscos de Adoecimento - Itra: instrumento auxiliar de diagnóstico de indicadores críticos no trabalho. In A. M. Mendes (Org.), Psicodinâmica do trabalho (pp. 111-126). São Paulo, SP: Casa do Psicólogo.

Mendes, A. M., \& Morrone, C. F. (2002). Vivências do prazer-sofrimento e saúde psíquica no trabalho: trajetória conceitual e empírica. In A. M. Mendes, L. O. Borges, L. O., \& M. C. Ferreira (Orgs.), Trabalho em transição, saúde em risco (pp. 25-42). Brasília, DF: Editora UnB.

Mendes, A. M., \& Morrone, C. F. (2010). Trajetória teórica e pesquisas brasileiras sobre prazer e sofrimento no trabalho. In A. M. Mendes (Org.), Psicodinâmica e clínica do trabalho: temas, interfaces e casos brasileiros (pp. 29-52). Curitiba, PR: Juruá Editora.

Meyer, J. P., \& Allen, N. J. (1991). A Three-component Conceptualization of Organizational Commitment. Human Resource Management Review, 1, 61-89.

Milhome, J. C., \& Rowe, D. E. O. (2018). Comprometimento e entrincheiramento organizacional: possíveis correlações. Gestão. org - Revista Eletrônica de Gestão Organizacional, 16(1), 69-77.

Moura, A. F. G., Silva, M. R., \& Carvalho, L. C. (2019). Comprometimento organizacional: um estudo com servidores e não servidores do Tribunal de Contas de Mato Grosso do Sul. Desafio Online, 7(1), 43-67.

Oliveira, J. B. Resiliência e controle do stress em juízes e servidores públicos (Tese de Doutorado). Centro de Ciências da Vida, Pontifícia Universidade Católica de Campinas, Campinas, SP.

Paiva, K. C. M., Falce, J. L., \& Muylder, C. F. (2013). Comprometimento organizacional: comparando servidores e terceirizados de uma fundação pública de pesquisa em saúde. Revista Economia \& Gestão, 13(33), 73-89.

Peci, A. (2020, março 05). Burocracia irracional legal. Valor Econômico. Recuperado de https://valor.globo.com/opiniao/coluna/burocraciairracional-legal.ghtml

Pfeffer, J. (2018). Dying for a Paychech: How Modern Management Harms Employee Health and Company Performance. New York, NY: Harper Collins Publishers.

Rodrigues, A. C. A., \& Bastos, A. V. B. (2009). Problemas conceituais e empíricos na pesquisa sobre comprometimento organizacional: uma análise crítica do modelo tridimensional de J. Meyer e N. Allen. In Anais do 32 Encontro da Associação Nacional de Pós-Graduação e Pesquisa em Administração, São Paulo, SP.

Rodrigues, A. P. G.; Alvares, K. P. (2020). Vínculos organizacionais: uma análise em relação ao desempenho. Revista Gestão e Planejamento, 21(1), 156-171.

Rodrigues, A. P. G., \& Bastos, A. V. B. (2013). Os vínculos de comprometimento e entrincheiramento presentes nas organizações públicas. Revista de Ciências da Administração, 15(36), 143-158.

Rodrigues, A. P. G., \& Bastos, A. V. B. (2015). Entrincheiramento organizacional. In K. Puente-Palacios, \& A. L. A. Peixoto (Eds.), Ferramentas de diagnóstico para organizações e trabalho: um olhar a partir da psicologia (pp. 107-120). Porto Alegre, RS: Artmed.

Rogge, J. F. N., \& Lourenço, M. L. (2015). A resiliência humana no ambiente acadêmico de cursos stricto sensu. Raimed - Revista de Administração IMED, 5(3), 291-301.

Sabbag, P. Y. (2017). Resiliência: competência para enfrentar situações extraordinárias na sua vida profissional. Rio de Janeiro, RJ: Alta Books.

Salgado, C. C. R., Aires, R. F. F., \& Santos, F. J. S. (2018). Dialética do "prazer e sofrimento": a relação de mestrandos e doutorandos com seu trabalho acadêmico. Contextus - Revista Contemporânea de Economia e Gestão, 16(2), 113-145.

Santos, A. P. (2017). Comprometimento e entrincheiramento em carreiras do setor público: estudo exploratório e confirmatório. Cadernos Gestão Pública e Cidadania, 22(73), 355-378.

Silva, E. E. C., \& Bastos, A. V. B. (2015). Consentimento organizacional. In K. Puente-Palacios, \& A. L. A. Peixoto (Eds.), Ferramentas de diagnóstico para organizações e trabalho: um olhar a partir da psicologia (pp. 92-106). Porto Alegre, RS: Artmed.

Silva, L. M. T., Medeiros, C. A. F., \& Enders, W. T. (2011). Avaliação da cultura organizacional: um contraponto entre as abordagens quantitativas e qualitativas. Interface - Revista do Centro de Ciências Sociais Aplicadas, 8(2), 123-140.

Silva, P. M. M., Lima, A. N. C., \& Leone, N. M. C. P. G. (2015). Entrincheiramento organizacional: percepção de empregados de uma agência bancária. Raimed - Revista de Administração IMED, 5(2), 111-120

Silva, R. C. D., Tomazzoni, G. C., \& Costa, V. M. F. (2018). Comprometimento e entrincheiramento organizacionais: uma análise comparativa com duas instituições de ensino superior. Gestão.org Revista Eletrônica de Gestão Organizacional, 16(1), 57-68.

Simosi, M. (2013). Trajectories of Organizational Commitment: A Qualitative Study in a Greek Public Sector Organization. International Journal of Cross Cultural Management, 13(1), 111-130.

Stoverink, A. C., Kirkman, B. L., Mistry, S., \& Rosen, B. (2018). Bouncing Back Together: Toward a Theoretical Model of Work Team Resilience. Academy of Management Review, 45(2), 395-422. Recuperado de https://doi.org/10.5465/amr.2017.0005

Taleb, N. N. (2012). Antifragile: Things that Gains from Disorder. New York, NY: Ramdom House.

Taleb, N. N. (2018). Skin in the Game: Hidden Asymmetries in Daily Life. New York, NY: Ramdom House. 
Teixeira, A. R. N., \& Queiroz, R. D. (2013, agosto). A importância da resiliência no contexto organizacional. Psicologado. Recuperado de https://psicologado.com.br/atuacao/ psicologia-organizacional/a-importancia-da-resiliencia-no-contextoorganizacional.

Tomazzoni, G. C., Costa, V. M. F., Antonello, C. S., \& Rodrigues, M. B. (2020). Os vínculos organizacionais na percepção de gestores: comprometimento, entrincheiramento e consentimento. Revista de Administração Contemporânea, 24(3), 245-258.
Van Breda, A. D. (2018). A Critical Review of Resilience Theory and its Relevance for Social Work. Social Work, 54(1), 1-18. Recuperado de http://dx.doi.org/10.15270/54-1-611

Vidal, D. N., \& Rodrigues, A. P. G. (2016). Vínculos organizacionais: estudo de caso no 13으 batalhão de bombeiros militar. Revista Gestão e Planejamento, 17(1), 4-18.

Vieira, A. A., \& Oliveira, C. T. F. (2017). Resiliência no trabalho: uma análise comparativa entre as teorias funcionalista e crítica. Cadernos EBAPE.BR, 15(esp.), 409-427.

Fabio Faiad Bottini

ORCID: https://orcid.org/0000-0002-6547-435X

Doutorando em Administração na Universidade Federal de Minas Gerais (UFMG/FACE/CEPEAD). E-mail: fabiofaiad@bol.com.br

Kely César Martins de Paiva

ORCID: https://orcid.org/0000-0002-5185-9072

Doutora em Administração; Professora Associada na Universidade Federal de Minas Gerais (UFMG/FACE/CAD); Bolsista de Produtividade em Pesquisa do CNPq- Nível 2 (Processo 312539/2018-5). E-mail: kelypaiva@face.ufmg.br

Ricardo C. Gomes

ORCID: https://orcid.org/0000-0002-4164-5986

Ph.D. em Gestão Pública; Professor Adjunto na Escola de Administração de Empresas de São Paulo da Fundação Getulio Vargas (FGV EAESP); Bolsista de Produtividade em Pesquisa do CNPq- Nível 1D (Processo 305497/2019-7).E-mail: ricardo.gomes@fgv.br 